Harvard Data Science Review • Special Issue 1: COVID-19:

Unprecedented Challenges and Chances

\title{
A Conversation With Larry \\ Bacow on the Impact of \\ COVID-19
}

\section{Lawrence Bacow ${ }^{1}$ Xiao-Li Meng ${ }^{2,3}$ Liberty Vittert ${ }^{4}$}

1'Office of the President, Harvard University, Cambridge, Massachusetts, United States of America,

${ }^{2}$ Department of Statistics, Faculty of Arts and Sciences, Harvard University, Cambridge, Massachusetts, United States of America,

${ }^{3}$ Harvard Data Science Review, Harvard Data Science Initiative, Harvard University, Cambridge, Massachusetts, United States of America,

${ }^{4}$ Washington University in St. Louis

Published on: May 14, 2020

DOI: https://doi.org/10.1162/99608f92.a9c8d801

License: Creative Commons Attribution 4.0 International License (CC-BY 4.0). 


\section{ABSTRACT}

Harvard Data Science Review’s Editor-in-Chief, Xiao-Li Meng, and Media Feature Editor, Liberty Vittert, sat down with Lawrence Bacow, the $29^{\text {th }}$ President of Harvard University. Following President Bacow's COVID19 recovery, he joined the editors to discuss the data used behind both the decisions to close and to open the university in stages, how economists contemplate the concept of risk and the value of life, and the impact of COVID-19 on higher education and society in general. This interview was conducted online on May 11, 2020.

\section{This interview is the first in HDSR's Conversations with Leaders series.}

HDSR includes both an audio recording and written transcript of the interview below. The transcript that appears below has been edited for purposes of grammar and clarity.

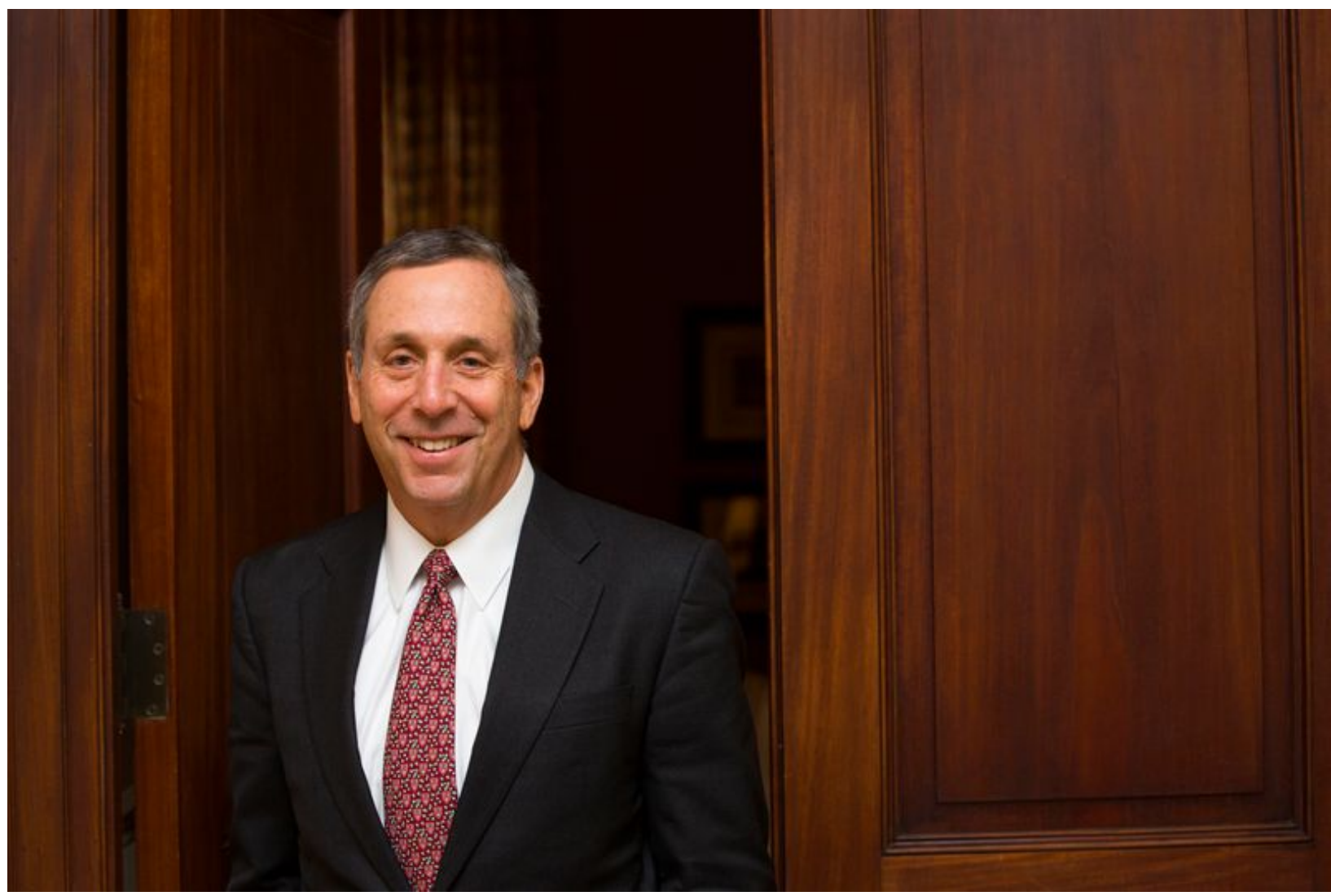


Xiao-Li Meng (XLM): Larry, thank you so much for taking time out of your impossible schedule to talk to us. This is also our first recording, so thank you for letting us use you as a guinea pig.

Larry Bacow (LB): [Thumbs up] Well, might as well, since everybody else does it. [Laugh]

XLM: Let's just jump into the question right away, because we do have quite a few questions to ask you. Harvard was one of the first universities to close. I'm sure that was not an easy decision. As statisticians, we can't resist asking you, was there any particular quantitative evidence or risk assessment that you and your team used, or any sort of evidence that was very helpful for your decision-making?

LB: Well, there a number of factors that went into it. We had been following the coronavirus quite closely since it first broke out in China, because - as you know so well, Xiao- $\mathrm{Li}$ - we have many students and faculty who travel regularly back and forth to China, and we were concerned about transmission of infection. We had also followed the breakout in other countries in Europe, and specifically Italy and Spain, which had been stressed by ever-growing numbers of infected individuals and subsequent deaths. In the four days preceding our announcement, the number of reported cases in Massachusetts, if memory serves me correctly, went from 13 to 28 to 42 to 91 . You, of course, will recognize the growth rate essentially had doubled daily, but from a small base, and this had repeated what we had seen in other countries. Moreover, other countries had seen it continue to grow exponentially. So, what forced the decision in our case was that spring break was coming on Friday, and we worried that if students left campus and went off to do what they normally did during spring break and then returned, that we would face a difficult situation. We figured that if we didn't have the infection on campus at that point, we would, and moreover, it would be difficult to control.

Dormitories are essentially cruise ships at anchor, or, another way to look at them, as one of my colleagues says - you can also think of them as nursing homes for the young. But they are petri dishes for infection. In this particular case, the cost of being wrong was asymmetrical, and that greatly influenced my thinking. If we made a decision to send everybody home and it turned out we were premature, we were wrong, we would inconvenience a lot of people. We would squander a lot of resources. That was the cost of being wrong in that direction, but if we waited and we were wrong, then it was likely that people would die. So that actually made the decision much simpler, and it was also the case I recognized at the time that other institutions would soon be in a similar position. We had access to some of the best experts in epidemiology, infectious disease, virology and public health. And I thought if we acted and we acted quickly, we might actually make it easier for other institutions to do the same.

Liberty Vittert (LV): Larry, it must have been a difficult decision to close in the first place, but it also must be just as tough a decision to figure out when to reopen. Are there sorts of specific data that you're also looking at to decide when to reopen? Is it the same metrics or different metrics that you look at for that decision? 
LB: Actually, it was an easier decision to close than to decide when to reopen. We had an action-forcing deadline. As I said on the decision to close, that was students leaving for spring break. Candidly, at the time, we did not realize how bad this pandemic would be in the United States, but we had some indication that it had the potential for being quite serious.

The decision to reopen is a tougher decision because it falls along a continuum, and it's not a binary choice. Reopening can mean lots of different things, and, in fact, we will reopen in stages. We're already working on trying to get our research enterprise started. The people who work in laboratories, for example, are used to working in controlled conditions with controlled substances. The first thing which we hope to do is to restart our labs. If we do that, it will mean that we'll have some graduate students working in those labs with their faculty members. The next thing which we would do would be to reopen libraries and archives in museums, but also strictly for research purposes. It would involve social distancing. It would involve carefully-scheduled hours so that those facilities were not overcrowded. Labs would work multiple shifts. We'll learn a lot when we do that. As we think about reopening the campus, it's really a question of staging a reopening over time.

Yes, we're looking at data. We're looking at the evolution of the pandemic itself. That data is still shrouded in some uncertainty because we still don't have a good sense of what proportion of the population has been infected, since so many people are infected but asymptomatic. Until we get widespread sampling of the broader population, we'll still be largely in the dark in terms of the proportion of the population that's been infected, but that is data that is collectable. That uncertainty can be resolved. With some pretty simple statistics, one can sample a huge population or to have a pretty good sense of what proportion of people are infected.

There are more profound uncertainties that are much, much harder to get our arms around. This has to do with when we will have cheap, effective, accurate, and quick testing, and there's a lot of progress being made on that front, but until we can satisfy all of those conditions, that limits our capacity to bring people back on campus. Another unknown is when we will have effective therapies that are widely available for this disease. I think everybody is in agreement that a vaccine is, at best, a year away just given the logistics of what it would take to manufacture a vaccine, even if one had an effective one right now, and we don't. The uncertainties having to do with the availability of cheap, quick, effective, and available testing will limit our capacity to bring people back. We're watching how that evolves. We're looking at the availability of effective treatments for the disease that could greatly reduce morbidity and mortality, and then we're also looking at the availability of personal protective equipment, which would affect the decision for when we bring people back and in what form.

LV: Wow, that's a lot to think about—a lot of different data to think about to make those sorts of decisions. Moving away from specifically your role as the president and going into your role as a scholar in economics and public policy, we all see in the news all the time these social and economic impacts of coronavirus, but my father always says you worry about the wrong thing. So, is there anything you see that we aren't anticipating or that is going to become the most difficult to understand that you see moving ahead in terms of social and economic impacts? 
LB: Well, you know, every economist wishes they had a crystal ball. I don't, so it's hard to say what it is that we should be worrying about, that we're not worrying about at the moment. You know, we do our best to look over the horizon and see around corners, to mix metaphors. One of the things which we are doing right now is we've got a group of our economists working in collaboration with our epidemiologists to try and model different pathways towards reopening the economy that are a function of how they are likely to influence the spread of this disease over time. And, you know, just trying to understand the impact of different types of strategies and policy interventions. Jim Stock in the Economics Department is working with colleagues at the Chan School of Public Health on that, and I think they're generating some interesting analysis. Longer-term, there are going to be profound consequences of all of this, and I suspect that scholars will be studying this for ages trying to unpack and understand the longer-term implications. I mean, we're doing some natural experiments right now.

My wife Adele has observed — and I think she's absolutely correct — that she believes that the big winners of all this are going to be professional women, because now that men have been forced to work from home, they understand that it's possible to be productive without spending 60 or 70 hours a week in the office. So, women who in the past may have dropped out of the labor force, or who've been forced on the labor force because we were less inclined to be flexible in the way in which we organize work, are now going to have more opportunities than they might have had previously. I think, more generally, we are going to take a different attitude towards work, and how it's organized, and where it is done. Will we travel as much? Probably not, now that we understand that we've developed the tools and the technology which allow us to engage with people at a distance in ways that are not quite the same as being in the same room with somebody but are pretty good. I think academics will have a rich mother lode of material to mine for many years to come. That includes statisticians, economists, sociologists, anthropologists, psychologists, demographers, and others as well.

LV: Going back to this idea of natural experiments, if you want to come up with a silver lining, like Adele's observation with professional women, is there a way to take advantage of the opportunity that we have to create our own experiments within this environment—something like designing a study to reduce the carbon footprint — that we would never have the chance to do otherwise?

LB: Well, you know, Liberty, it's a really, really good question. Candidly, I've been so focused just on how we sort through all the uncertainties and the different strategies and approaches for dealing with the fall that I haven't had time really to think about that. I'm also sorting through the financial implications of this university, which are profound. I'm pretty much occupied full-time on those issues. I will say, though, that we are working in collaboration with our peers at MIT and BU and Tufts to try and identify a variety of different approachesexperiments, if you will— to how we might utilize testing in a variety of settings to see if we can accelerate the way in which we bring back students to our campus. So, there we are trying to consciously approach this challenge by thinking in experimental terms and imagining a number of different approaches of using testing in a residential setting, having to do with the frequency of testing in combination with personal protective 
equipment, which might allow us to engage in less social distancing than we might have to do otherwise. We are trying to generate new data and evidence to inform different strategies going forward.

XLM: Larry, I want to follow up on the issue of socioeconomic impact and particularly in your role as an economist. There has been quite a bit of talk about the trade-off. If you keep locked down, there is an impact on lives as well, such as people suffering cancers need to be treated in a timely fashion. How do you balance the one life versus another? For me, there is always a fascinating and a troubling question of how does an economist think about the value of a life? How do you do that kind of calculation?

LB: You ask two economists that question and you'll probably get three different answers. I don't think we can ignore it. And we don't. In all sorts of situations, we make implicit calculations of the value of life. The market does this all the time. If you look at what people will spend, for example, to avoid exposure to certain types of environmental hazards or occupational hazards, those are fraught because some people have choices that others don't in the marketplace. You or I might spend a lot to avoid exposure to coal dust, but if you're a coal miner in West Virginia and you've got very few choices in life, you're willing to engage in that.

There are other examples that we can find even closer to home where people make choices all the time. Years ago - and I haven't looked at the data in a long time - the fastest growing county in Massachusetts was Plymouth County, and if you tried to understand why, it was because property taxes were quite low in Plymouth County. Why? Because a Pilgrim nuclear power plant paid the bulk of property taxes and some people made the choice, implicit or explicit, that they'd rather have low property taxes and live in reasonable proximity to a nuclear power plant than to pay higher property taxes and live someplace else. Implicitly, they're putting a value on their own life when they make that calculation. So we do this all the time. And what we do is that we manage risk. We don't eliminate it completely. And I don't think anybody is talking about strategies or approaches to restarting the economy that would represent zero risk to people. I think the way in which we're thinking about it for the university is, what risks can we reasonably manage and mitigate? People have different attitudes towards risks which they incur willingly on their own-riding a motorcycle, going skiingversus risks which are imposed upon them unwittingly or by third parties, in which we have no control.

In the case of the coronavirus, it falls somewhere in between because we do have some capacity to control our own exposure by whether or not we wear masks, whether or not we socially isolate. But it gets complicated when we start designing systems, and the university is a system, in which we start to impose certain requirements on people. I think people are likely to react differently if we give them options than if they don't have them. It gets quite complicated because students, as a group, are healthy. They are in an age cohort which has relatively modest risk of mortality, certainly from this disease. But that's not true as one moves up the age cohort and it's also not true for those who have preexisting conditions. A standard question in environmental health and safety in designing regulatory policy is: do we design policies for those who are most at risk to a disease to protect them, or design it for the average person and then seek to protect those who are most at risk through other strategies. That's basically the problem that we have here. Our students are not much at risk, but 
that's not true for our faculty and staff who are much older and many of whom have preexisting conditions. As we think about how to restart campus, we need to spend a lot of time thinking about that.

LV: In that same vein of the fact that there are always going to be people at risk at a place like Harvard, or at any university for that matter, do you see a new normal being created for the higher education system? Is there something that's going to have to change and be different? Or do you think there's a chance that we can go back to normal?

LB: I think it's going be a while before we go back to normal, if one describes 'normal' as the status quo before COVID-19. When we do bring people back to campus in large numbers, I suspect it's highly likely that they will be masked, many of them will be wearing gloves, and they will be tested and tested frequently. There will have to be methods to keep people apart in densely populated settings. I was just reading an article yesterday about the risks associated for people who participate in choral groups. Turns out when you bring a bunch of people together and they start singing together that it turns out to be quite dangerous. This has consequences for all sorts of things, not just choral groups on campus, but religious gatherings where large numbers of people are present and singing enthusiastically; for political conventions, where thousands of people coming together and cheering, is functionally the equivalent of singing; large scale athletic events; etc. Anything which brings groups together in which people scream and shout, at least until there's a vaccine, are going to be looked at quite differently than we might have looked at it before.

XLM: Who would have thought these things are dangerous, right? Let me follow up on a question about universities and natural experiment. For our educators, probably the biggest natural experiment at this moment is online education versus residential education. Many of us thought it couldn't be done, but now we are all doing it. From a data science perspective, how are you measuring or evaluating the effectiveness of online education so that later you can decide, in a very rational fashion, if part of the university's functions can be really delivered online, and hence fundamentally change the way that education is delivered?

LB: What happened this spring didn't really permit us to do much in the way of evaluation. The faculty had to pivot in an incredibly short period of time, basically 10 days from when we announced it to when they had to start teaching online. The courses were not designed to be online, and faculty received only the briefest of instruction in how to do this. I think, far more interesting, will be what happens over time, because I suspect that as we start to bring students back, there will be courses that are both taught online and taught in personthe same course. Now, this has been done before in the form of a structured experiment. In fact, it was one that I participated in as a scholar. The organization, ITHAKA, did some work, probably now would have been eight or nine years ago, where Bill Bowin and I and a few others looked at the teaching of a statistics course in which we randomly assigned students to an online version of a course and an in-class version of the course, and then tried to track how students performed in the course. The result was published. Interestingly, there weren't radically different outcomes in that case. Now, that was one course. It doesn't say that it's equally true for all teaching. 
One of the things that's quite hard to do in teaching online is to teach very very difficult, abstract material. It's the higher-level subjects that turn out to be far more challenging to teach. It's not just that you're in an online setting, it's also that far fewer students are taking those courses and, as a result, we can't invest an equivalent amount in the pedagogy to create online content for a course that's going to be taken by fewer students. Let's say, if you were to teach an online course in quantum field theory, where the number of students who would be taking that course nationally would be probably a thousandth of the number of students who might be taking a course in introductory statistics or calculus course. The point I want to make is that our ability to invest in content will be radically different for subjects that are thinly taught as opposed to subjects that are frequently and robustly taught. So it's just the case that one cannot extrapolate from one single experiment that was done nine years ago to say online education is the same as in-person.

It's also the case that so much of what students learn in a class is actually not learned directly from the teacher but due to peer effects as students study and work with other students. We're still learning how to create and develop content and structures which facilitate that peer-to-peer learning that occurs so naturally, when students gather and they work together to work through difficult problems or to discuss material outside the class. Then there are all the things which faculty do which are difficult to replicate in an online setting. It's one thing to convey content, but faculty do a lot more than that with their students. They inspire their students. They push their students. They mentor their students. They create lifelong relationships with their students. And it's hard to do that if you've actually never shared a meal with a student. If you've never worked in a setting with a student where you're writing a paper together or doing laboratory work together, or field work together. I think it's those things which we need to figure out how to recreate in an online setting that have evolved so naturally over literally a thousand years of students, at least metaphorically, sitting at the feet of their teachers and learning together and from them.

XLM: Well, thank you very much, Larry, and I know we are at the end of this precious time. I do have one fun question for you, the last one. If you are given a crystal ball and you are allowed to ask one question, what would you ask?

LB: When are we going to start playing baseball again?

LV: [Laugh] The Red Sox, obviously.

XLM: [Laugh] Wonderful one! Thank you again, Larry. We really appreciate it, and we wish you well. I know you have so many things to do, and we are grateful that you are the leader of Harvard to guide us to go through this really difficult time. Thank you again!

LB: Thank you, Xiao-Li. Thank you, Liberty. I enjoyed this and I hope both you both of you do a better job of staying healthy than I did!

XLM: [Laugh] So far. Thank you! 
LB: Take care!

\section{Disclosure Statement}

Lawrence Bacow, Liberty Vittert, and Xiao-Li Meng have no financial or non-financial disclosures to share for this interview.

(C2021 Lawrence Bacow, Liberty Vittert, and Xiao-Li Meng. This interview is licensed under a Creative Commons Attribution (CC BY 4.0) International license, except where otherwise indicated with respect to particular material included in the interview. 